\title{
Design and Virtual Testing of American Football Helmets-A Review
}

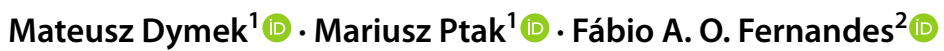

Received: 29 April 2021 / Accepted: 24 June 2021 / Published online: 8 July 2021

(c) The Author(s) 2021

\begin{abstract}
This paper aims to review the recent progress in the research carried out by scientists worldwide regarding American Footballers' head injuries and head protective equipment, focusing on the role of computation methods, mainly finite element method application to American Football helmet design and testing as well as head injury biomechanics. The helmet technology has been constantly improved, and it is driven by market competition, medical records, coaches and athletes' self-awareness. With finite element analysis and computational resources development, it is possible to develop more accurate brain models to recreate American Footballers' head impacts. This method seems to be an excellent simulation tool to verify the helmet's ability to absorb energy and enable the researchers to have an insight into head kinematics and tissue-level injuries. The work is focused on head injuries in American Football as the sport becomes more popular across the globe. Additionally, a reference to the development and newest technology is presented. The review's proposed approach gathers studies presented within the last decade regarding the coupling of finite element brain models with helmets in standardised or on-field conditions. The synthesis of the existing state of the art may enhance the researchers to continue investigating the athlete's trauma and improve the protective gear technology to minimise head injuries. The authors presented numerous studies regarding concussions and the newest findings from the last decade, including Finite Element Head models (FEHm) with American Football helmet simulations. All the studies were searched through Google Scholar, Scopus and ResearchGate databases.
\end{abstract}

\section{Introduction}

In the beginning, the authors would like to highlight the terminology used in this article related to head and brain injuries. The public tends to associate the negative symptoms to "brain injury" (judged as more serious) rather than to "head injury" (less severe, in their view), despite the fact the description may be related to the same injury event [1]. Thus, the authors will use the terms head/brain injury interchangeably regarding brain injury.

Mateusz Dymek

mateusz.dymek@pwr.edu.pl

Mariusz Ptak

mariusz.ptak@pwr.edu.pl

Fábio A. O. Fernandes

fabiofernandes@ua.pt

1 Faculty of Mechanical Engineering, Wroclaw University of Science and Technology, Lukasiewicza 7/9, 50-371 Wroclaw, Poland

2 TEMA-Centre for Mechanical Technology and Automation, Department of Mechanical Engineering, University of Aveiro, Campus de Santiago, 3810-193 Aveiro, Portugal
At the professional and amateur level of contact sports such as martial arts, it is a challenge to avoid brain trauma, thus the number of brain injuries in sports is significant [2]. However, not only martial arts injury is highlighted in the head injuries statistics in sport. Each year, there are many reported concussions in American Football across the United States (Finite element (FE) models have been used as a research tool for over a decade to investigate brain kinematics and injury mechanisms (Table 1) [24]. Various detailed FE brain and helmet models have been validated and used by researchers to evaluate the probability of injury by verifying brain strain, stress or intracranial pressure (ICP). Even though this approach is rather theoretical, as there is no study backing the results with, e.g. cadaver studies, it can significantly benefit and increase the knowledge.) [3-6]. Lincoln et al. [7] examined over 2600 concussions in over 10000000 exposures at the high school level (incident rate 0.24 per 1000 ). American Football accounted for more than half of all concussions, and it had the highest incidence rate (0.60). Women football had the most concussions among the ladies' sports and the second-highest incidence rate of all 12 sports (0.35) [7]. A similar issue of numerous head injuries was reported in Rugby Union or Australian Football, where 
Table 1 Summary of studies investigating head injury statistics in American Football

\begin{tabular}{ll}
\hline Authors and year of study & Objective of the study \\
\hline Beckwith et al. [5] & Correlation of the measures of head impact biomechanics recorded when tested on the linear impactor \\
Songbai et al. [6] & Investigation of the sensitivities of regional strain-related responses to kinematic variables of accelerations \\
Lincoln et al. [7] & Examination of the incidence and relative risk of concussion in 12 high school boys' and girls' sports \\
Kucera et al. [11] & $\begin{array}{l}\text { Identification of traumatic brain and spinal cord injury deaths during 2005-2014 among high school and } \\
\text { college football players }\end{array}$ \\
Crisco et al. [13] & Quantification of the frequency and location of head impacts \\
Brolinson et al. [14] & Utilisation of an in-helmet system that measures and records linear head accelerations \\
Rowson et al. [15] & Characterisation of the tolerance to the rotational kinematics resulting from helmeted head impacts \\
Viano et al. [16] & Simulation in laboratory tests of impacts causing concussions \\
\hline
\end{tabular}

players do not wear the protective equipment as in American Football [8-10].

American Football is played at high school, collegiate and professional level in various countries, including the United States of America. The athlete's safety is a vibrant topic as popularity has significantly increased around the world. Despite the mandatory protective equipment-such as helmets and shoulder pads-injuries are caused frequently by direct impacts between players and against the ground $[5,11,12]$. Crisco et al. [13] recorded the total number of impacts in three football teams during the 2007 fall season of the National Collegiate Athletic Association (NCAA). The number of impacts players received was abnormally distributed and varied by team, session type, and player position. The maximum number of head impacts for a single player on each team was 1022 (team A), 1412 (team B), and 1444 (team C). For the 2003 and 2004 seasons, Brolinson et al. [14] recorded 11604 head impacts with 2 970 occurring in 22 games and 8634 in 67 practices. The impacts were measured from 52 different players covering the majority of offensive and defensive positions. In the three brain injuries, a peak linear head acceleration of 55.7, 136.7, and $117.6 \mathrm{~g}$ was reported by Rowson et al. [15] as the authors implemented an acceleration-measuring device in 335 football helmets. Between 2007 and 2009, in NCAA, a total of 300977 head impacts were recorded and analysed in this study. Of these impacts, 286636 head impacts were recorded using the Head impact telemetry system (HIT) and 14341 head impacts were recorded using the 6 degrees of freedom (DOF) measurement device. A total of 57 concussions were compiled for this analysis. Viano et al. [16] underline that although there are already efforts to reduce impact accelerations, further study of head kinematics after impact is necessary. It was proven that even small reductions in velocity might have a significant influence on concussion probability reduction. Not only the rates of traumatic brain injuries (TBI) in players should be underlined but also the number of former players diagnosed with chronic traumatic encephalopathy (CTE) [3, 17-23].
Finite element (FE) models have been used as a research tool for over a decade to investigate brain kinematics and injury mechanisms (Fig. 1) [24]. Various detailed FE brain and helmet models have been validated and used by researchers to evaluate the probability of injury by verifying brain strain, stress or intracranial pressure (ICP). Even though this approach is rather theoretical, as there is no study backing the results with, e.g. cadaver studies, it can significantly benefit and increase the knowledge.

The criteria of helmets validation are based on longitudinal and rotational acceleration. The Severity Index (SI), based on linear acceleration acting on the head's center of gravity, is an example of the criteria employed. These threshold criteria are proposed by the National Operating Committee of Standards for Athletic Equipment (NOCSAE) [25-28]. These criteria seem to be a simplification of the complex impact kinematics. It must be noted that the human brain and skull cannot be simply treated as rigid structures. Additionally, during the impact, the momentum of the brain tissue differs from the skull's momentum.

The academic institutes that develop numerical American Football helmet models are e.g.: University of Waterloo, Arizona State University, University of Alabama and University of Virgina, Wayne State University, Mississippi State University, Wroclaw University of Science and

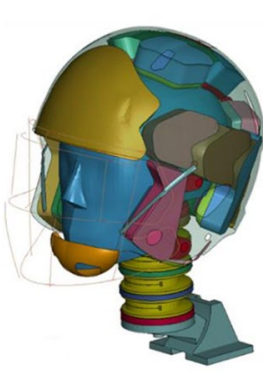

(a)

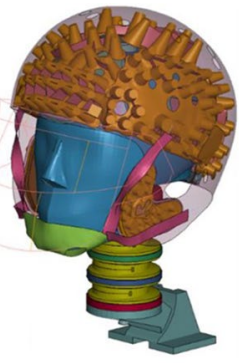

(b)

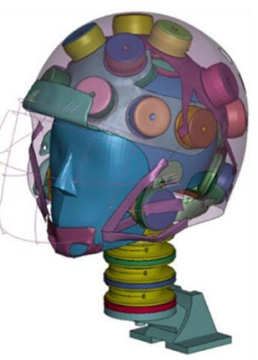

(c)
Fig. 1 Finite element models with different energy-absorbing technologies: a foam, b buckling cone, $\mathbf{c}$ air damper. Based on [29] 
Technology, University of Aveiro, KTH Royal Institute of Technology. The vast majority of researchers use the finite element helmet models shared by the NFL "Play smart, Play safe" programme. The idea of this founded research was to obtain various helmet models and share them across the public via Biocore to encourage scientists to improve the understanding of trauma to the head of NFL players, to collaborate with helmet manufacturers and other companies, entrepreneurs and universities to develop highly safe protective equipment. The exemplary Ridell Revolution Speed Classic model (Fig. 1a) is composed of 53 separate parts and 147384 elements. The validation of each material models was based on compression, shear and tension tests. A total of 62 simulations were performed with the full helmet model, using either an HIII or NOCSAE headform to validate the helmet [29].

The initial helmet function was to prevent the skull from fractures since these injuries are usually very severe and lead to disability or death. The limitation of the helmet design is the mass and size-i.e. the inertia and moments of inertia-the parameters, which influences the head and neck biomechanics [30].

In this review, the authors collected the studies from the last decade regarding finite element analysis of American Football helmets impacts with implemented brain models. There are numerous different approaches to collect the data and recreating using the analysis. Collecting and critically reviewing the existing research will highlight the gaps within the existing literature, and it shall motivate the researchers to continue investigating athletes' trauma and improve protective gear technology to minimise head injury.

\section{Design and Function}

The helmet structure can be divided into two major parts. The hard outer shell is responsible for distributing the impact force over the liner's area. Due to this phenomenon, the energy absorption is increased. Consequently, the probability of head injury is decreased. Additionally, the rigid structure acts as a penetration resistance and initial shock absorber. The second part is attached inside the helmet's shell-the energy-absorbing material, usually polyurethane foam. The primary function is to absorb impact energy and reduce the head's deceleration by viscoelastic compression $[31,32]$.

These are the main characteristics of a helmet, independently of the type and application. Although, these define the design in terms of materials, geometries, etc., by having different criteria, the advances or new configurations/systems developed for one type of helmet, can be redesigned for other applications. For instance, the solutions designed to mitigate the head injuries caused by rotational acceleration among motorcyclists/bikers [33].

The structure cannot be heavy as it will decrease the comfort and potentially increase spinal injuries probability. The perfect balance between the inner layer's stiffness and thickness must be met to maximise the energy absorption [34]. For example, when the liner is excessively soft, the head may compress it completely upon impact, which results in no further energy-absorbing capacity of the material. Since the outer liner is a rigid structure, the head suddenly stops, which results in high accelerations induced to the brain. On the contrary, if impact speed is lower than the one for which it was designed, the head decelerates more abruptly than necessary given the available thickness [33].

During the impact, the head is subjected to numerous acceleration magnitudes; thus, the brain may move inside the skull due to its inertia. Depending on the acceleration, the movement may lead to severe injuries as the brain moves backwards inside the skull (during frontal impact), squeezing the tissue near the impact site and stretching the tissue on the opposite side of the head. Next, the brain bounces in the opposite direction stretching the tissue near the impact site and squeezing on the other side (Fig. 2). This coup and contrecoup behaviour can be explained as the brain is suspended inside the skull in cerebrospinal fluid (CSF) $[35,36]$. However, the CSF usually does not provide enough cushioning for high energy impacts [37]. The forces during head impact may cause significant damage to brain tissue and bridging veins structure causing brain swelling and bleeding [33].

\section{Helmet History}

The American Football helmet history reaches back to the end of the XIX century. The very first use of a helmet during the game was documented in 1893 in an Army-Navy game [38]. In the beginning, American Football helmets were mostly leather and shaped in beehive, flat-top or dog-ear style (Fig. 3) [39]. From this point, helmets have significantly evolved and biomechanical researchers have better

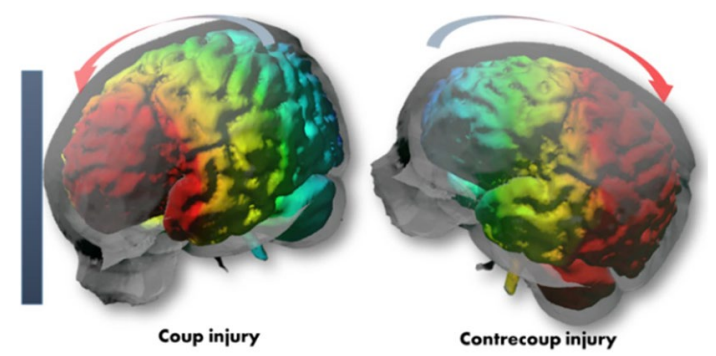

Fig. 2 Head impact with primary (coup) and secondary impact (contrecoup) 


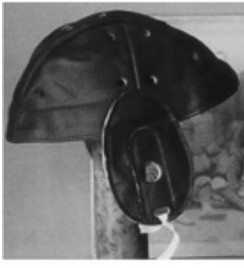

(a)

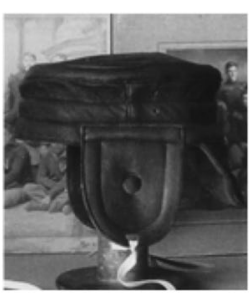

(b)

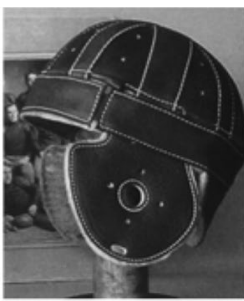

(c)
Fig. 3 Leather American Football helmet: a beehive style, b flat-top style, c dog-ear style from 1920s. Based on [39]

insight into the head's biophysical characteristics and the development of kinematic head injury [40].

The American Football helmet is designed to protect the players head during tackles and ground impacts. However, the structure cannot fully protect from injuries to the head and neck. The use of helmets became mandatory in 1939, first in NCAA, and later in 1940 for National Football League (NFL) [38]. With time, helmet engineering has been improved and the use of metal alloys and polymers became common to provide more protection. The first helmets with a simple facemask one bar structure were introduced in 1951 and two-bar facemask design in 1958 (Fig. 4). Due to numerous head and spinal injuries occurring in American Football, the NOCSAE was founded in 1969, and the first safety standards for helmets were established in 1973 [41-43]. Since then, helmet technology has improved rapidly [44]. According to Schneider et al. [45], football helmets should be explicitly constructed based on an anatomic knowledge of the skull and brain to understand the mechanical principles involved in head injuries. Schneider stated that the helmet's outer shell should be constructed to cover either the skull's fragile areas, which might fracture or cover specific portions of the intracranial contents, most frequently vulnerable to head injuries that may result in concussion [39].

Since then, leading brands of American Football helmets (e.g. Riddell, Schutt, Xenith) have endeavoured to enhance

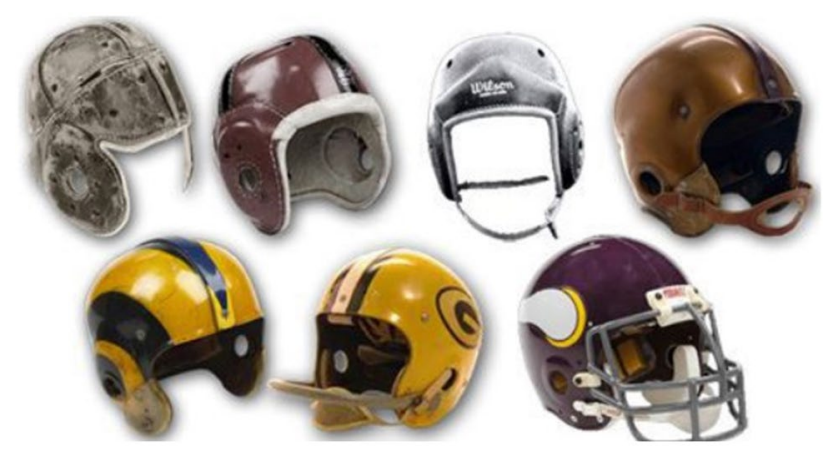

Fig. 4 A chronology of American Football helmets: upper left - the oldest design [46] the design and players safety (Fig. 5). Currently, there are multiple models available on the market. Each company investigates the rigid structure's energy dissipation: the outer shell and the soft layer inside the helmet, i.e. TPU (thermoplastic polyurethane) cushioning, or low-density foam coupled with a polymer layer. The innovative mechanism is used by Schutt company in the F7 model [47]. The proposed solution is to implement the tectonic plates strategically on the outer shell that move independently of the helmet shell. This solution increases the helmet's performance against rotational forces [47]. Riddell proposes another solution-the shell is manufactured so that there is a cut-out on the front. During impacts, the plate bends and dissipates the energy [48]. Both producers point out how important it is to have a perfectly fitted helmet with a faceguard. The other companies have unique ideas to enhance the stabilization of the helmet on the player's head. Xenith focused on the padding inside the helmet, which are dual-stage shock absorbers that work together in response to linear and rotational forces. The pads can move individually during the impact, being compressed separately or moving laterally [49].

\section{Helmet Regulations}

\subsection{NOCSAE Regulations}

NOCSAE standards, introduced in 1973, required using a head model that mimics the human head's response to impact. The standards are based on the helmet falling in a guided fall. In each case, the helmet is positioned on a head form, which is a human-like representing dummy (Fig. 6). It is constructed to provide the data during impact tests. The goal of the regulations was to measure the football helmet's capacity to withstand repeated blows of various magnitudes under a wide variety of playing conditions without any sacrifice in protective quality [39]. The drop impact is specified by six different points of impacts and four different velocities: $3.46,4.23,4.88,5.46 \mathrm{~m} / \mathrm{s}$ ) [27, 50-52] any pneumatic ram test conducted on the medium headform shall not exceed $6000 \mathrm{rad} / \mathrm{s}^{2}$ [27].

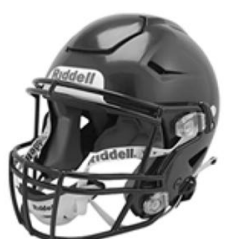

(a) Riddell SpeedFlex Diamond

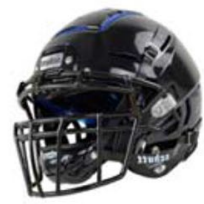

(b) Schutt F7 LTD

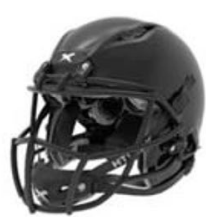

(c) Xenith Shadow XR
Fig. 5 Newest models for leading helmet brands: a Riddell SpeedFlex Diamond, b Schutt F7 LTD, c Xenith Shadow XR 
(a)

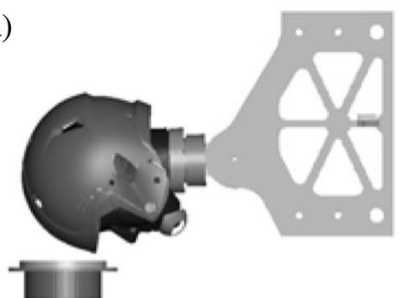

(b)

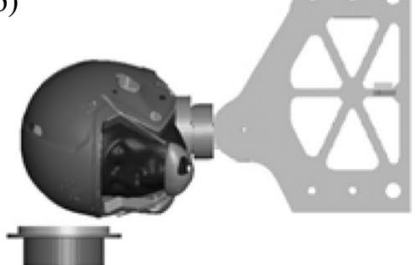

(c)

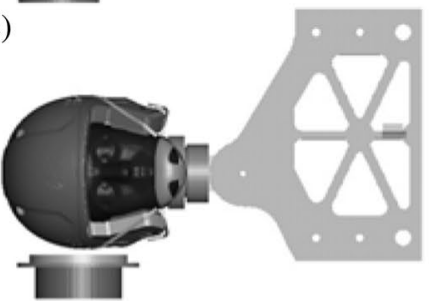

(d)

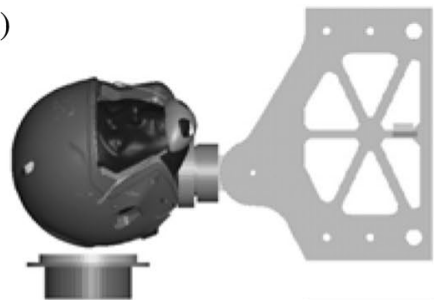

(e)

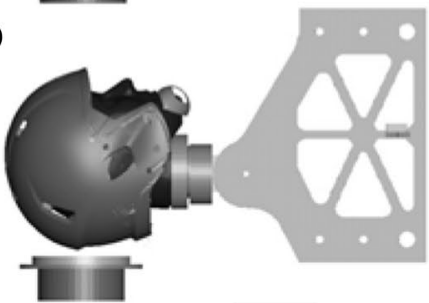

(f)

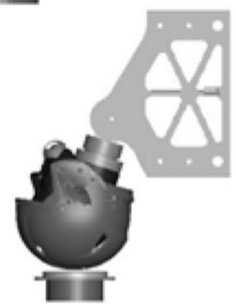

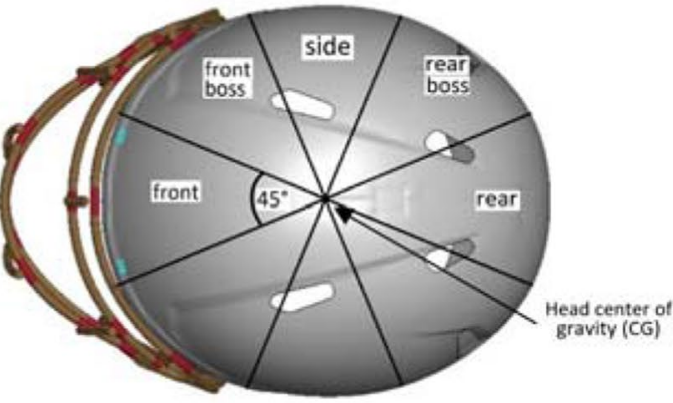

Fig. 6 NOCSAE linear drop setup on the left: A-Front, B-Front Boss, C-Side, D-Rear Boss, E-Rear, F-Top; Impact location bins on the right, based on [27]

\subsection{STAR Evaluation System}

In the STAR evaluation system, proposed by Virginia Tech University, helmet's performance is measured by the capacity to reduce linear and rotational acceleration of the head resulting from a set of impacts. The tests are performed by a pendulum impactor with four impact locations and three velocities: 3.1, 4.9, and $6.4 \mathrm{~m} / \mathrm{s}$. Another significant difference between the NOCSAE and STAR tests is the helmeted medium NOCSAE head custom-fit to a Hybrid III neck. The head and neck are mounted to a 5-degree-of-freedom Biokinetics slide table with a $16 \mathrm{~kg}$ sliding mass.

Currently, the drop impact is performed with a humanlike anthropomorphic test device (ATD), equipped with accelerometers in the headform's center of gravity. The registered data is longitudinal and rotational accelerations measured through an accelerometer. Furthermore, the SI is calculated as (1):

$\mathrm{SI}=\int_{0}^{t} A^{2.5} d t$

where: $A$ is the instantaneous resultant acceleration expressed as a multiple of $g$ (acceleration of gravity), $d t$ is the time increments in [s], the integration is carried over the essential duration $(t)$ of the acceleration pulse. The peak SI shall not exceed the value of 1200 , and the peak rotational acceleration of this setup allows for linear and rotational motion to be generated and represents the head, neck, and torso of a 50th percentile male. Further, the STAR rating is calculated by Eq. (2) to predict concussion incidence of one player over a season [53-55].

$\mathrm{STAR}=\sum_{L=1}^{4} \sum_{V=1}^{3} E(L, V) \cdot R(a, \alpha)$

Equation (2) bases on laboratory tests that represent the range of on-field impacts seen in college American Football and associates with each impact the number of times it would occur over one season (exposure) as well as the associated probability of concussion (risk). The STAR value is found by multiplying the predicted on-field exposure $(E)$ at each impact location $(L)$ and velocity $(V)$ by the risk of concussion $(R)$ for that impact using the peak resultant linear acceleration $(a)$ and rotational acceleration $(\alpha)$ from laboratory impacts [53]. All of the presented above helmets have a rating equal to 5 stars (highest possible). However, the results vary from 0.75 for Schutt F7 LTD, 1.69 for Riddell SpeedFlex Diamond and 1.91 for Xenith Shadow XR, where the performance rating is from lowest to highest (the lower, the better). 


\section{Finite Element Research Analysis}

The review can be defined into two main groups of interest. The first group contains the research based on laboratory tests, where the helmet is subjected to either impactor or a drop impact. These tests are to mimic validation tests. With this approach, researchers investigate the helmet's stress or strain distribution and verifying if the threshold criteria for head injury are met. The second approach is based on recreating the real-life impacts. The data are recorded during practices, games, or assumed scenarios based on observation of multiple impacts (Table 2). The experimental data are mostly recorded by either dummy sensors or accelerometers attached inside the helmet in both scenarios. The specialists from Stanford University presented a novel mouthguard approach [56, 57]. The researchers investigated whether the motion is precisely transferred onto the skull with developed wearable devices to measure head and helmet kinematics. Since the skin lower stiffness raised concerns, the instrumented mouthguards were introduced to measure the head kinematics. Thanks to this approach, the recorded accelerations and velocities are exclusive of the skull.

\subsection{Validation Tests with Brain Model Implementation}

The implementation of the whole numerical human model for head injury verification is not common in the current literature, mainly due to the computational effort. However,
Darling et al. [58] presented a Global Human Body Model Consortium (GHBMC) [59-61] full-body model coupled with the Riddell Attack Revolution Youth helmet (size Large) (Riddell 2014) model. It is necessary to mention that according to the NOCSAE, the facemask and retention system are not included. The full-body model enables including all relevant anatomical features in studying the brain response to head-helmet interaction scenarios. The helmet numerical model was validated according to convergence analysis [62] and important energy-related parameters that are an integral part of explicit finite element analysis [63-65]. Moreover, the model was validated using the experimental method. The impactor drop test proved with the use of vertical acceleration of the impactor that the model was able to recreate the salient features of the experimental acceleration profiles.

A different approach is presented by Bruneau and Cronin [66], Post et al. [67] and Kuo et al. [68]. These scientific groups investigated the head motion with a helmet to prescribed skull kinematics. The first approach was conducted using linear impactor or drop impact. A number of impact tests (Cronin: 6; Post: 27; Kuo: 108) with recorded kinematics were conducted. However, Kuo et al. [68] recorded the data using an instrumented mouthguard. Prescribing rigidbody kinematics to the head centre of gravity and treating the skull as a rigid allowed the authors to apply angular and linear head velocities measured from the first approach [57, 74-76]. Additionally, two neck muscle activation schemes were investigated by Bruneau and Cronin [66] of the full model, representing maximally and minimally tensed neck.

Table 2 Discrete brain models used in the reviewed research

(58]


The brain model utilized in these studies is composed of different regions, such as grey matter, white matter, corpus callosum, falx, tentorium, cerebellum, brainstem and midbrain.

Alizadeh et al. [69] propose a damping element consisting of liquid with a linear impactor test. First, the optimal damping force to absorb the impact energy from a ballistic mass is determined to show that the constant force profile does in fact minimize the brain tissue strain. Second, a novel energy absorption technology of liquid shock absorbers is proposed to approach this minimum force level. Using FE analysis, an optimal energy absorber is then integrated into a helmet. The NFL standard linear impact test is then simulated, and this new helmet's performance is compared with four other helmets with different energy absorption technologies using kinematic metrics, brain FE criteria, and injury risk curves.

All of the mentioned above numerical analyses have shown that the loading conditions replicating NOCSAE standards are dangerous [58, 66-69]. However, implementing numerical brain models has demonstrated that these thresholds conditions will not prevent the athletes from potential brain injury despite acceptable SI scores. By analysing head to head impact occurrences of mild traumatic brain injury (mTBI) with finite element model, Zhang [77] predicted $50 \%$ probability of injury at $7.8 \mathrm{kPa}$ (Huber-MisesHencky stress: H-M-H) and principal strain of 0.19 whereas Willinger and Baumgartner [78] predicted injury at $18 \mathrm{kPa}$ (von Mises stress) by analysing brain tissue in car accidents with finite element model and comparing to known injury cases [77, 78]. Another test performed by Pfister [79] shows axonal injury and neural brain cell death occurs when applying principal strain of $20-70 \%$ and strain rates in the range of 20-90 $\mathrm{s}^{-1}$ [79]. Darling et al. [49] obtained the highest response values for the brainstem in the crown impact and oblique frontal impact. The maximum response values, according to Darling et al. [49], are summarised in (Table 3).

According to Bruneau et al. [66], within the helmet and impactor impacts, minimal increases in peak maximal principal strain (up to 0.04) were observed with balanced muscle activation compared to the "no activation" condition. The increase in maximal principal strain due to balanced muscle activation was lower in the lateral orientation (an increase of 0.01 in $9.3 \mathrm{~m} / \mathrm{s} \mathrm{impact)} \mathrm{compared} \mathrm{to} \mathrm{the} \mathrm{frontal} \mathrm{and} \mathrm{rear}$ orientations. The whole-brain cumulative strain damage measure exhibited more significant increases due to muscle activation than maximal principal strain. However, these were still small with a maximum rise of 0.07 observed in cumulative strain damage measure. There was no notable change in the magnitude or timing of angular velocity with muscle activation.

The case with the most significant limitations, presented by Alizadeh et al. [69], evaluated how a liquid shock absorber, tuned for idealized performance in a benchtop setup, would perform when integrated into a football helmet (Fig. 7). The fluid shock absorber's operation inside the helmet can be investigated by looking at the damping force generated by an integrated fluid damper during an impact on the back of the helmet. This study's major limitation is that idealized constant force damping elements were used in the full helmet simulation. In contrast, some of the idealities may be unfeasible for physical implementation. Nevertheless, it was found that there was approximately a $30 \%$ reduction in peak kinematics and maximal principal strain using the liquid helmet, which corresponded to a $75 \%$ reduction in the number of

Table 3 Maximum response values, according to Darling et al. [58]

Crown impact

\begin{tabular}{llll}
\hline & Brainstem & Midbrain & Corpus callosum \\
\hline Max principal strain [-] & 0.045 & 0.045 & 0.023 \\
Max shear strain [-] & 0.044 & 0.037 & 0.021 \\
Strain rate [ms ${ }^{-1}$ ] & 0.027 & 0.019 & 0.0099 \\
Shear strain rate [ms ${ }^{-1}$ ] & 0.027 & 0.018 & 0.0097 \\
H-M-H stress [Pa] & 476 & 345 & 131 \\
Tresca stress [Pa] & 274 & 196 & 76 \\
\hline Frontal oblique impact & & & Corpus callosum \\
\hline & Brainstem & Midbrain & 0.076 \\
\hline Max principal strain & 0.088 & 0.029 & 0.071 \\
Max shear strain & 0.08 & 0.028 & 0.0098 \\
Strain rate [ms ${ }^{-1}$ ] & 0.016 & 0.017 & 0.0082 \\
Shear strain rate [ms & & 291 \\
H-M-H stress [Pa] & 0.017 & 0.016 & 166 \\
Tresca stress [Pa] & 659 & 443 & 253 \\
\hline
\end{tabular}




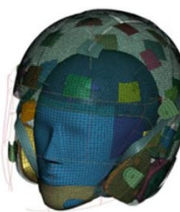

(a)

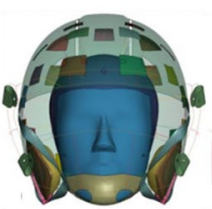

(b)

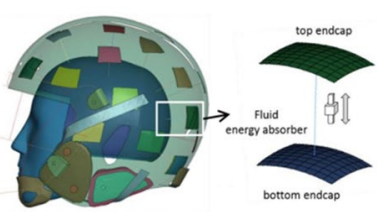

(c)

(d)
Fig. 7 FE model of the helmet with fluid shock absorber. The helmet shell is shown transparent to allow the shock absorbers to be viewed: a FE meshed helmet model, b frontal view (middle), c side view, d Fluid energy absorber. The top endcap is in contact with the helmet shell and the bottom endcap is in contact with the head. Endcaps are constrained to be parallel and have linear motion along with the damper element. [69]

expected concussions from the NFL test. Further, the proposed liquid shock absorber helmet reduces accelerations just below this sharp injury threshold, explaining how relatively small changes in angular kinematics can have considerable clinical significance in reducing concussion.

Dymek et al. [70] presented a different approach, where the ICP is investigated in 8 different NOCSAE setups. Additionally, the ICP calculated with the $\alpha$ HEAD model is compared to the Head Injury Criterion (HIC) calculated with the Hybrid III Head-Neck model. The authors underline the disadvantages of criteria based on longitudinal acceleration as most impacts in sports, racing or urban situations are oblique. This is why the longitudinal acceleration is relatively low-mostly below the HIC thresholds-while values of rotational acceleration are critical. Bearing in mind that skull bones are more vulnerable to side impacts than longitudinal impacts, this can significantly affect the probability of head injury [80]. This study proves that even though HIC values are permissible (HIC threshold value is 1000), more robust parameters such as the presented ICP exceed threshold values (app. $237 \mathrm{kPa}$ ) in each tested configuration $[27,81]$. The ratio of $3 \mathrm{D}$ finite elements in the modelled brain tissue exceeding the threshold criterion varies from 20 to $29 \%$. However, it is necessary to point out that $\alpha \mathrm{HEAD}$ is based mainly on a tetrahedral mesh approach - thus, the studies shall be continued with more advanced models.

\subsection{Impact Based on Real-Life Events}

Honarmandi et al. [71] proposed a study based on a simple contact model, where the angle of impact, $\theta$, varied from 0 to $45^{\circ}$ for each player in a helmet-to-helmet impact (Table 4). The coefficient of restitution was established as $\mathrm{e}=0.45$, where $\mathrm{e}=1.0$ is perfectly elastic and $\mathrm{e}=0$ is perfectly plastic condition. The time of simulation was established to $7.2 \mathrm{~ms}$. The conservation of momentum was applied to the system of two players along with the coefficient of restitution to obtain the velocities after impact. Then, the impulsive force was obtained by employing the principle of impulse and momentum on one of the players. The interesting aspect considered is the variation of mass for different positions on the field, combining realistic scenarios and a portion of players' masses. To summarise, there were 28 separate cases.

Ghajari et al. [72] presented three distinct types of injurious scenarios, a helmet-to-helmet impact in American Football, an occipital head impact due to a fall from ground level, and a road traffic accident involving a helmeted motorcyclist. Ghajari et al. [72] underline that the developed brain model will allow a detailed investigation of brain deformation during impact loading, especially the differences between sulci and gyri deformation. The velocity of the striking player was estimated by analyzing the video footage of the game. Then, the collision was reconstructed in the lab by representing the players with dummies, launching one dummy towards the other at the estimated impact velocity, and measuring the struck dummy's head's accelerations. The finite element model predicted a patchy distribution of strain and strain rate within the brain, with both strain and strain rate being greatest in the sulci. It was confirmed that the distinction between the maximal strain and strain rate in the sulci and gyri by mapping out these fields at the grey-white matter interface [82, 83].

A notable number of 148 reconstructed head impacts from video footage of American Football games is presented by Zimmerman et al. [73]. The players were separated into three different position profiles based on magnitude and frequency impacts. The study proves that the possibility of concussion varies between positions, for example, defensive backs or wide receivers are exposed to a large magnitude, low-frequency impacts and lineman to low magnitude,

Table 4 Scenarios concerning positions on the field and impact locations presented by Honarmandi et al. [71]

\begin{tabular}{|c|c|c|c|c|c|c|}
\hline \multicolumn{7}{|l|}{ Four scenarios } \\
\hline $\begin{array}{l}\text { Linebacker vs. } \\
\text { wide receiver }\end{array}$ & \multicolumn{2}{|c|}{$\begin{array}{l}\text { Lie Element Human Head Model } \\
\text { Partially Validate } \\
\text { nebacker vs. running back }\end{array}$} & \multicolumn{2}{|c|}{ Safety vs. wide receiver } & \multicolumn{2}{|c|}{ Safety vs. running back } \\
\hline \multicolumn{7}{|l|}{ Seven scenarios } \\
\hline Head X vs. head Y & $\begin{array}{l}\text { Head X vs. half } \\
\text { body Y }\end{array}$ & $\begin{array}{l}\text { Half body X vs. } \\
\text { head X }\end{array}$ & $\begin{array}{l}\text { Half body X vs. } \\
\text { half body Y }\end{array}$ & $\begin{array}{l}\text { Full body X vs. } \\
\text { half body Y }\end{array}$ & $\begin{array}{l}\text { Half body X vs. } \\
\text { Full body Y }\end{array}$ & $\begin{array}{l}\text { Full body X vs. Half } \\
\text { body Y }\end{array}$ \\
\hline
\end{tabular}


high-frequency. It was found that player position in American Football affects the magnitude of strain and strain rate across the brain, particularly in sulci. This is likely due to the effect of player position on impact kinematics. The large strain and strain rate may explain the higher concussion rate in offensive and defensive linemen positions. However, the impact frequency is likely a critical factor in producing the neurodegenerative processes at lower strains than those required to produce concussion-like symptoms. This is a limitation of the study, which needs to be addressed when more information is available on the repetitive effects of forces on primary and secondary progressive damage to the brain.

\section{Discussion}

The American Football helmet aims to protect the head from mechanical injuries and reduce the probability of traumatic brain injury. The different energy-absorbing technologies are implemented in various presented solutions to dissipate impact energy. The current development tendency is to focus on the soft inner layer of energy-absorbing materials. Schutt company introduced an interesting technology of tectonic plates, strategically placed on the outer shell that moves independently of the helmet. Both producers and NOCSAE indicate that football helmets may not fully protect the player. Other research communities have made similar conclusions in the literature [58, 84-92].

The reviewed study regarding finite element analysis has shown that current helmet validation standard tests may not cover the common spectrum of head injuries and further, there is no decision on the best update (Table 5). The main conclusion is that there is no precise predictor of what the cause of injury might be. Various injury criteria based on accelerations, strains or stresses are still under investigation.
A similar conclusion is presented in the literature concerning, i.e. motorcycle helmets [33, 93].

Nevertheless, one of the issues that will certainly continue to be studied is chronic traumatic encephalopathy (CTE) in football players. The increasing number of former players being diagnosed with such pathology will have an impact in the future of head protection in sports, particularly in contact sports with repetitive head impact as is the case of American Football. Changes to mitigate such a serious problem can go from game rules to head impact protection. Another interesting point would be an analysis of forces acting on the neck and their interpretation in terms of Neck Injury Criteria (NIC) or Normalized Neck Injury Criteria (Nij).

CTE is being linked with repeated brain injuries and long-term brain changes that reflect in the form of symptoms such as memory loss, impaired judgment, aggression and depression [3, 21-23]. Therefore, CTE diagnosis in a short-term period is a challenge. Although there are already reported cases in living individuals [94, 95], most are diagnosed post-mortem. FE models and virtual testing can be put together to understand the mechanisms of repeated head impacts that cause minor impairment, but their cumulative effect might result in long-term issues. The attenuation of a wide range of impacts, for different impact energies, reflecting on the impact velocity and a wide range of strain rates, and even on the impact surface and object, might be the key for safer helmets in contact sports. Computational modelling plays the role of enabler, making it possible to optimize the helmet for several scenarios.

In the review, there are presented studies with eight different FE head models. However, there are more available head models in the literature, such as Worcester head injury model [96], Yet Another Head Model [97] or Wayne state University brain injury model [98]. Each academic institute, developing the brain models, focuses on different strategies, which results in the variety of geometry and, thus, results. To

Table 5 Summary of reviewed research

\begin{tabular}{|c|c|c|c|}
\hline Authors & Impact conditions & FEHM & Investigated parameters \\
\hline Darling et al. [58] & Crown and oblique front & THUMS & Strain, von Mises stress \\
\hline Bruneau and Cronin [66] & Lateral, Frontal and Rear & Composed of 8 elements & $\begin{array}{l}\text { Maximal principal } \\
\text { strain, neck activation } \\
\text { influence }\end{array}$ \\
\hline Post et al. [67] & 5 different point of contact & UCDBTM & $\begin{array}{l}\text { Maximal principal } \\
\text { strain, von Mises } \\
\text { stress }\end{array}$ \\
\hline Kuo et al. [68] & 6 different point of contact & WHIM & Strain \\
\hline Alizadeh et al. [69] & 8 different point of contact & KTH Royal Institute of Technology & Maximal principal strain \\
\hline Dymek et al. [70] & 8 different point of contact & $\alpha \mathrm{HEAD}$ & ICP \\
\hline Honarmandi et al. [71] & 24 different point of contact & 2D model & Stress, Strain \\
\hline Ghajari et al. [72] & 1 impact & Imperial College London & Strain rate \\
\hline Zimmerman et al. [73] & 148 impacts & Imperial College London & Strain rate \\
\hline
\end{tabular}


share a bigger picture of the head injuries studies, it would be beneficial to implement all available FE head models and compare the results.

Currently, the results in the literature show a trend where the regions that incur the largest deformations are generally in areas opposite to the impact site. These results could also shed some light on the possible reason why there are so many different symptoms of concussion. The results indicate that depending on the impact's location, a different brain region would incur larger deformations and be susceptible to injury [67]. The loading conditions presented were not intended to replicate impacts that cause mTBI but to replicate NOCSAE standard impacts assumed as dangerous impact conditions. According to injury thresholds, values obtained in these loading conditions may lead to potential injury conditions through high strain rates observed in the corpus callosum, midbrain and brainstem [58].

\section{Conclusions}

The helmet design is a multidisciplinary task that incorporates knowledge from different fields, from the engineering side with materials and design to medicine with the understanding of injury biomechanics. Currently, advances in helmet design have been made thanks to advances in these areas, where computational tools play an essential role. For instance, at the moment, one of the most sounding technologies in helmet design is the VICIS Zero1 helmet, with an innovative liner for American Football helmets that may be effective in reducing diagnosed concussions and reducing symptoms [99]. In a study conducted by Rivara and Gause [99], the number of coach-reported concussions was fewer in the season in which players wore the VICIS Zero1 helmet and on average the players felt better and had fewer headaches.

Finite element head models can play a groundbreaking role in the design of football helmets, considering some of the conclusions obtained in the studies carried out by Camarillo research group. In one study, high tensile strains were found in the corpus callosum during the reconstruction of a head impact in an American Football game where the player suffered a concussion [100]. Therefore, FE head models can be used to optimize football helmets to mitigate serious outcomes. Additionally, it is expected that advances in computational biomechanics will help to deeply understand the mechanisms of injury through the employment of advanced numerical models at the level of fluid-structure interaction or multiscale modelling. There is a tendency to create models with the highest accuracy and lowest computational time. Unfortunately, these two aspects do not go in pair. Hopefully, with the computer units development, it will be possible to analyse the most complicated models within hours.
The numerical biomechanics research has made a major contribution to understanding the mechanisms of injuries and designing sport protective equipment such as helmets.

Regulations for American Football helmets are important but should be improved to target these issues and help prevent concussions and their repetition. It is necessary to remember that the threshold criteria are mainly based on skull fracture caused by the impact. Back in the days, the assumption was as such that if there is a skull fracture, then brain damage is inevitable. With today's medical and engineering knowledge, it is possible to distinguish different brain injuries and their mechanisms. Therefore, test standards should reflect the later scientific developments.

Funding The publication was developed as part of project LIDER/8/0051/L-8/16/NCBR/2017 funded by the National Centre for Research and Development, Poland.

\section{Declarations}

Conflict of interest The authors declare no conflict of interest.

Ethical approval The author declares that this article complies with the ethical standards.

Open Access This article is licensed under a Creative Commons Attribution 4.0 International License, which permits use, sharing, adaptation, distribution and reproduction in any medium or format, as long as you give appropriate credit to the original author(s) and the source, provide a link to the Creative Commons licence, and indicate if changes were made. The images or other third party material in this article are included in the article's Creative Commons licence, unless indicated otherwise in a credit line to the material. If material is not included in the article's Creative Commons licence and your intended use is not permitted by statutory regulation or exceeds the permitted use, you will need to obtain permission directly from the copyright holder. To view a copy of this licence, visit http://creativecommons.org/licenses/by/4.0/.

\section{References}

1. McKinlay A, Bishop A, McLellan T (2011) Public knowledge of 'concussion' and the different terminology used to communicate about mild traumatic brain injury (MTBI). Brain Inj 25:761-766. https://doi.org/10.3109/02699052.2011.579935

2. Meehan WP (2018) Kids, sports, and concussion : a guide for coaches and parents, 2nd Edition

3. Saal JA (1991) Common American football injuries. Sport Med. https://doi.org/10.2165/00007256-199112020-00005

4. O'Keeffe E, Kelly E, Liu Y et al (2020) Dynamic blood-brain barrier regulation in mild traumatic brain injury. J Neurotrauma 37:347-356. https://doi.org/10.1089/neu.2019.6483

5. Beckwith JG, Greenwald RM, Chu JJ (2012) Measuring head kinematics in football: correlation between the head impact telemetry system and hybrid III headform. Ann Biomed Eng 40:237-248. https://doi.org/10.1007/s10439-011-0422-2 
6. Ji S, Zhao W, Li Z, McAllister TW (2014) Head impact accelerations for brain strain-related responses in contact sports: a model-based investigation. Biomech Model Mechanobiol 13:1121-1136. https://doi.org/10.1007/s10237-014-0562-z

7. Lincoln AE, Caswell SV, Almquist JL et al (2011) Trends in concussion incidence in high school sports. Am J Sports Med 39:958-963. https://doi.org/10.1177/0363546510392326

8. Tierney GJ, Simms C (2019) Predictive capacity of the MADYMO multibody human body model applied to head kinematics during Rugby union tackles. Appl Sci 9:726. https://doi. org/10.3390/app9040726

9. Hasegawa Y, Kawasaki T, Miyazaki Y et al (2020) Changes of the cervical spine in response to head-first impact in rugby: a finite element analysis. Juntendo Med J. https://doi.org/10.14789/ jmj.2020.66.JMJ20-OA04

10. Cogoluenhes L, Evin M, Forodighasemabadi A et al (2019) A modelisation of quantification of head and neck risks associated with tackles in rugby union. Comput Methods Biomech Biomed Engin 22:S273-S275. https://doi.org/10.1080/10255 842.2020 .1714910

11. Kucera KL, Yau RK, Register-Mihalik J et al (2017) Traumatic brain and spinal cord fatalities among high school and college football players-United States, 2005-2014. MMWR Morb Mortal Wkly Rep 65:1465-1469. https://doi.org/10.15585/ mmwr.mm6552a2

12. Rowson S, Daniel RW, Duma SM (2013) Biomechanical performance of leather and modern football helmets. J Neurosurg 119:805-809. https://doi.org/10.3171/2013.3.JNS121735

13. Crisco JJ, Fiore R, Beckwith JG et al (2010) Frequency and location of head impact exposures in individual collegiate football players. J Athl Train 45:549-559. https://doi.org/10.4085/ 1062-6050-45.6.549

14. Brolinson PG, Manoogian S, McNeely D et al (2006) Analysis of linear head accelerations from collegiate football impacts. Curr Sports Med Rep 5:23-28. https://doi.org/10.1097/01. CSMR.0000306515.87053.fa

15. Rowson S, Duma SM, Beckwith JG et al (2012) Rotational head kinematics in football impacts: an injury risk function for concussion. Ann Biomed Eng 40:1-13. https://doi.org/10. 1007/s10439-011-0392-4

16. Viano DC, Casson IR, Pellman EJ (2007) Concussion in professional football. Neurosurg 61:313-328. https://doi.org/10. 1227/01.NEU.0000279969.02685.D0

17. Casson IR, Viano DC, Powell JW, Pellman EJ (2010) Twelve years of national football league concussion data. Sport Heal A Multidiscip Approach 2:471-483. https://doi.org/10.1177/ 1941738110383963

18. Boden BP, Tacchetti RL, Cantu RC et al (2007) Catastrophic head injuries in high school and college football players. Am J Sports Med. https://doi.org/10.1177/0363546507299239

19. Gessel LM, Fields SK, Collins CL et al (2007) Concussions among United States high school and collegiate athletes. J Athl Train 42:495-503

20. Liu Y, Domel AG, Yousefsani SA et al (2020) Validation and comparison of instrumented mouthguards for measuring head kinematics and assessing brain deformation in football impacts. Ann Biomed Eng 48:2580-2598. https://doi.org/10. 1007/s10439-020-02629-3

21. Pellman EJ, Viano DC (2006) Concussion in professional football. Neurosurg Focus 21:1-10. https://doi.org/10.3171/ foc.2006.21.4.13

22. Arnason A, Sigurdsson SB, Gudmundsson A et al (2004) Risk factors for injuries in football. Am J Sports Med 32:5-16. https://doi.org/10.1177/0363546503258912

23. McIntosh AS, McCrory P (2005) Preventing head and neck injury. Br J Sports Med 39:314-318
24. Kraft RH, Mckee PJ, Dagro AM, Grafton ST (2012) Combining the finite element method with structural connectomebased analysis for modeling neurotrauma: connectome neurotrauma mechanics. PLoS Comput Biol 8:e1002619. https://doi. org/10.1371/journal.pcbi.1002619

25. Fernandes FAO, Alves de Sousa RJ, Ptak M, Wilhelm J (2020) Certified motorcycle helmets: computational evaluation of the efficacy of standard requirements with finite element models. Math Comput Appl 25:12. https://doi.org/10.3390/mca25 010012

26. Jamroziak K, Bajkowski M, Bocian M et al (2019) Ballistic head protection in the light of injury criteria in the case of the Wz.93 combat helmet. Appl Sci 9:2702. https://doi.org/ 10.3390/app9132702

27. National Operating Committee on Standards for Athletic Equipment (2019) Standart Performance Specification for Newly Manufactured Football Helmets

28. Gwin JT, Diamond SG, Halstead PD, Greenwald RM (2016) An Investigation of the NOCSAE Linear Impactor Test Method Based on In Vivo Measures of Head Impact Acceleration in American football. 132: https://doi.org/10.1115/1.4000249

29. Biocore Biocore Finite element models. https://biocorellc.com/ finite-element-models/. Accessed 23 Mar 2021

30. Sybilski K, Małachowski J (2021) Impact of disabled driver's mass center location on biomechanical parameters during crash. Appl Sci 11:1427. https://doi.org/10.3390/app11041427

31. Shuaeib FM, Hamouda AMS, Hamdan MM et al (2002) Motorcycle helmet. J Mater Process Technol 123:422-431. https://doi. org/10.1016/S0924-0136(02)00047-X

32. Liu D-S, Chang C-Y, Fan C-M, Hsu S-L (2003) Influence of environmental factors on energy absorption degradation of polystyrene foam in protective helmets. Eng Fail Anal 10:581-591. https://doi.org/10.1016/S1350-6307(03)00040-2

33. Fernandes FAO, Alves de Sousa RJ (2013) Motorcycle helmetsA state of the art review. Accid Anal Prev 56:1-21. https://doi. org/10.1016/j.aap.2013.03.011

34. Shuaeib FM, Hamouda AMS, Wong SV et al (2007) A new motorcycle helmet liner material: The finite element simulation and design of experiment optimization. Mater Des 28:182-195. https://doi.org/10.1016/j.matdes.2005.04.015

35. Toma M, Chan-Akeley R, Lipari C, Kuo S-H (2020) Mechanism of coup and contrecoup injuries induced by a knock-out punch. Math Comput Appl 25:22. https://doi.org/10.3390/mca25020022

36. Toma M, Nguyen PDH (2020) Coup-contrecoup brain injury: fluid-structure interaction simulations. Int J Crashworthiness 25:175-182. https://doi.org/10.1080/13588265.2018.1550910

37. Ptak M (2019) Pedestrian safety: a new method to assess pedestrian kinematics. Transp 34:41-51. https://doi.org/10.3846/trans port.2019.7081

38. Levy ML, Ozgur BM, Berry C et al (2004) Birth and Evolution of the Football Helmet. Neurosurg 55:656-662. https://doi.org/ 10.1227/01.NEU.0000134599.01917.AA

39 Levy ML, Ozgur BM, Berry C et al (2004) Birth and evolution of the football helmet. Neurosurg 55(3):656-662

40. Newman $\mathbf{J}$ (2005) The biomechanics of head trauma and the development of the modern helmet. How far have we really come.itle. In: Proceedings of the IRCOBI Conference. $p 10$

41. Bennett T (1977) The NFL's official encyclopedic history of professional football. Macmillan

42. Clarke KS, Powell JW (1979) Football helmets and neurotrauma-an epidemiological overview of three seasons. Med Sci Sports 11(2):138-145

43. Thompson N, Halpern B, Curl WW et al (1987) High school football injuries: evaluation. Am J Sports Med. https://doi.org/ $10.1177 / 036354658701500204$ 
44. Newman JA (2015) Design and Testing of Sports Helmets Biomechanical and Practical Considerations. In: Accidental Injury. Springer: New York, NY, pp 755-768

45. Schneider RC (1987) Football head and neck injury. Surg Neurol 27:507-508. https://doi.org/10.1016/0090-3019(87)90272-2

46. Jimmy Stamp (2012) Leatherhead to Radio-head: The Evolution of the Football Helmet. In: Smithson. Mag. https://www.smith sonianmag.com/arts-culture/leatherhead-to-radio-head-the-evolu tion-of-the-football-helmet-56585562/. Accessed 19 Apr 2021

47. Schutt Schutt F7 LTD Football helmet

48. Riddell Riddell SpeedFlex Football helmet

49. Xenith Xenith Shadow Football helmet

50. National Operating Committee on Standards for Athletic Equipment (2019) Football Helmet Standards Overview

51. National Operating Committee on Standards for Athletic Equipment (2019) What Players, Parents and Coaches Need to Know About Football Helmets

52. National Operating Committee on Standards for Athletic Equipment (2020) NOCSAE history. https://nocsae.org. Accessed 12 Nov 2020

53. Rowson S, Duma SM (2011) Development of the STAR evaluation system for football helmets: integrating player head impact exposure and risk of concussion. Ann Biomed Eng 39:21302140. https://doi.org/10.1007/s10439-011-0322-5

54. Rowson B, Rowson S, Duma SM (2015) Hockey STAR: a methodology for assessing the biomechanical performance of hockey helmets. Ann Biomed Eng 43:2429-2443. https://doi.org/10. 1007/s10439-015-1278-7

55. Pellman EJ, Viano DC, Withnall C et al (2006) Concussion in professional football: helmet testing to assess impact performance-part 11. Neurosurgery 58:78-95. https://doi.org/10. 1227/01.NEU.0000196265.35238.7C

56. Camarillo D, Mattson J, Flynn M et al (2013) Head contacts in collegiate football measured with an instrumented mouthguard. Br J Sports Med 47:e1.27-e1. https://doi.org/10.1136/bjsports2012-092101.33

57. Camarillo DB, Shull PB, Mattson J et al (2013) An instrumented mouthguard for measuring linear and angular head impact kinematics in American football. Ann Biomed Eng 41:1939-1949. https://doi.org/10.1007/s10439-013-0801-y

58. Darling T, Muthuswamy J, Rajan SD (2016) Finite element modeling of human brain response to football helmet impacts. Comput Methods Biomech Biomed Engin 19:1432-1442. https:// doi.org/10.1080/10255842.2016.1149574

59. Chatelin S, Constantinesco A, Willinger R (2010) Fifty years of brain tissue mechanical testing: From in vitro to in vivo investigations. Biorheology 47:255-276. https://doi.org/10.3233/ BIR-2010-0576

60. Bilston LE (2011) Brain tissue mechanical properties. Springer, Stud Mechanobiol Tissue Eng Biomater

61. Mao H, Zhang L, Jiang B et al (2013) Development of a finite element human head model partially validated with thirty five experimental cases. J Biomech Eng. https://doi.org/10.1115/1. 4025101

62. Roache PJ (1998) Verification and Validation in Computational Science and Engineering

63. Bansal S, Mobasher B, Rajan SD, Vintilescu I (2009) Development of fabric constitutive behavior for use in modeling engine fan blade-out events. J Aerosp Eng 22:249-259. https://doi.org/ 10.1061/(ASCE)0893-1321(2009)22:3(249)

64. Stahlecker Z, Mobasher B, Rajan SD, Pereira JM (2009) Development of reliable modeling methodologies for engine fan blade out containment analysis. Part II: Finite element analysis. Int J Impact Eng 36:447-459. https://doi.org/10.1016/j.ijimpeng.2008. 08.004
65. Deivanayagam A, Vaidya A, Rajan SD (2014) Enhancements to modeling dry fabrics for impact analysis. J Aerosp Eng 27:484490. https://doi.org/10.1061/(ASCE)AS.1943-5525.0000350

66. Bruneau DA, Cronin DS (2021) Brain response of a computational head model for prescribed skull kinematics and simulated football helmet impact boundary conditions. J Mech Behav Biomed Mater 115:104299. https://doi.org/10.1016/j.jmbbm. 2020.104299

67. Post A, Oeur A, Walsh E et al (2014) A centric/non-centric impact protocol and finite element model methodology for the evaluation of American football helmets to evaluate risk of concussion. Comput Methods Biomech Biomed Engin 17:17851800. https://doi.org/10.1080/10255842.2013.766724

68. Kuo C, Wu L, Zhao W et al (2018) Propagation of errors from skull kinematic measurements to finite element tissue responses. Biomech Model Mechanobiol 17:235-247. https://doi.org/10. 1007/s10237-017-0957-8

69. Alizadeh HV, Fanton MG, Domel AG, et al (2019) Prevention of Traumatic Brain Injury with Liquid Shock Absorption

70. Dymek M, Ptak M, Ratajczak M et al (2021) Analysis of HIC and hydrostatic pressure in the human head during NOCSAE tests of American football helmets. Brain Sci 11:287. https://doi.org/10. 3390/brainsci11030287

71. Honarmandi P, Sadegh AM, Cavallaro PV (2015) Modelling and impact analysis of football player head with helmet toward mitigating brain concussion. Int J Exp Comput Biomech 3:267. https://doi.org/10.1504/IJECB.2015.074732

72. Ghajari M, Hellyer PJ, Sharp DJ (2017) Computational modelling of traumatic brain injury predicts the location of chronic traumatic encephalopathy pathology. Brain 140:333-343. https:// doi.org/10.1093/brain/aww317

73. Zimmerman KA, Kim J, Karton C et al (2021) Player position in American football influences the magnitude of mechanical strains produced in the location of chronic traumatic encephalopathy pathology: A computational modelling study. J Biomech 118:110256. https://doi.org/10.1016/j.jbiomech.2021.110256

74. Siegmund GP, Guskiewicz KM, Marshall SW et al (2014) A headform for testing helmet and mouthguard sensors that measure head impact severity in football players. Ann Biomed Eng 42:1834-1845. https://doi.org/10.1007/s10439-014-1052-2

75. Campbell KR, Warnica MJ, Levine IC et al (2016) Laboratory evaluation of the gForce TRACKER ${ }^{\mathrm{TM}}$, a head impact kinematic measuring device for use in football helmets. Ann Biomed Eng 44:1246-1256. https://doi.org/10.1007/s10439-015-1391-7

76. Wu LC, Nangia V, Bui $\mathrm{K}$ et al (2016) In vivo evaluation of wearable head impact sensors. Ann Biomed Eng 44:1234-1245. https://doi.org/10.1007/s10439-015-1423-3

77. Zhang L, Yang KH, King AI (2004) A proposed injury threshold for mild traumatic brain injury. J Biomech Eng 126:226-236. https://doi.org/10.1115/1.1691446

78. Willinger R, Baumgartner D (2003) Numerical and physical modelling of the human head under impact - towards new injury criteria. Int J Veh Des 32:94. https://doi.org/10.1504/IJVD.2003. 003239

79. Pfister BJ, Weihs TP, Betenbaugh M, Bao G (2003) An in vitro uniaxial stretch model for axonal injury. Ann Biomed Eng 31:589-598. https://doi.org/10.1114/1.1566445

80 Zhang L, Yang KH, King AI (2001) Comparison of brain responses between frontal and lateral impacts by finite element modeling. J Neurotrauma 18(1):21-30

81. Ptak M (2019) Method to Assess and Enhance Vulnerable Road User Safety during Impact Loading. Appl Sci 9:1000. https://doi. org/10.3390/app9051000

82. Fischl B, Salat DH, van der Kouwe AJW et al (2004) Sequenceindependent segmentation of magnetic resonance images. 
Neuroimage 23:S69-S84. https://doi.org/10.1016/j.neuroimage. 2004.07.016

83. Fischl B (2012) FreeSurfer. Neuroimage 62:774-781. https://doi. org/10.1016/j.neuroimage.2012.01.021

84. Viano DC, Withnall C, Halstead D (2012) Impact performance of modern football helmets. Ann Biomed Eng 40:160-174. https:// doi.org/10.1007/s10439-011-0384-4

85. Bailey AM, McMurry TL, Cormier JM et al (2020) Comparison of laboratory and on-field performance of american football helmets. Ann Biomed Eng. https://doi.org/10.1007/ s10439-020-02627-5

86. Lamb L, Hoshizaki TB (2009) Deformation mechanisms and impact attenuation characteristics of thin-walled collapsible air chambers used in head protection. Proc Inst Mech Eng Part H J Eng Med 223:1021-1031. https://doi.org/10.1243/09544119JE IM573

87. Dean SW, Hoshizaki TB, Post A (2009) Impact attenuation characteristics of thin walled collapsible air chambers for use in protective helmets. J ASTM Int 6:101883. https://doi.org/10.1520/ JAI101883

88. Johnston JM, Ning H, Kim J-E et al (2015) Simulation, fabrication and impact testing of a novel football helmet padding system that decreases rotational acceleration. Sport Eng 18:11-20. https://doi.org/10.1007/s12283-014-0160-4

89. Giudice JS, Caudillo A, Mukherjee S et al (2020) Finite element model of a deformable american football helmet under impact. Ann Biomed Eng 48:1524-1539. https://doi.org/10.1007/ s10439-020-02472-6

90. Dymek M, Peliński J (2020) Numerical simulation of professional American football helmet with head model. Aktual Probl Biomech 13-20

91. Corrales MA, Gierczycka D, Barker J et al (2020) Validation of a football helmet finite element model and quantification of impact energy distribution. Ann Biomed Eng 48:121-132. https://doi. org/10.1007/s10439-019-02359-1

92. Post A, Kendall M, Cournoyer J et al (2018) Brain tissue analysis of impacts to American football helmets. Comput Methods Biomech Biomed Engin 21:264-277. https://doi.org/10.1080/10255 842.2018 .1445229
93. Fernandes FAO, Sousa RJAD (2015) Head injury predictors in sports trauma-A state-of-the-art review. Proc Inst Mech Eng Part H J Eng Med. https://doi.org/10.1177/0954411915592906

94. Nadia Kounang C (2017) Ex-NFL player confirmed as 1st case of CTE in living patient. https://edition.cnn.com/2017/11/16/health/ cte-confirmed-in-first-living-person-bn/index.html. Accessed 12 Oct 2020

95. Omalu B, Small GW, Bailes J et al (2018) Postmortem autopsyconfirmation of antemortem [F-18]FDDNP-PET scans in a football player with chronic traumatic encephalopathy. Neurosurg 82:237-246. https://doi.org/10.1093/neuros/nyx536

96. Zhao W, Ruan S, Li H et al (2012) Development and validation of a 5th percentile human head finite element model based on the Chinese population. Int J Veh Saf 6:91. https://doi.org/10.1504/ IJVS.2012.049024

97. Fernandes FAO, Tchepel D, Alves de Sousa RJ, Ptak M (2018) Development and validation of a new finite element human head model: Yet another head model (YEAHM). Eng Comput (Swansea, Wales) 35:477-496. https://doi.org/10.1108/ EC-09-2016-0321

98. Yang KH, Mao H, Wagner C, et al (2011) Modeling of the Brain for Injury Prevention. pp 69-120

99. Rivara FP, Gause E (2020) Coaches survey of VICIS zero1 helmet use in high school football. Ann Biomed Eng 48:517-518. https://doi.org/10.1007/s10439-019-02438-3

100. Hernandez F, Giordano C, Goubran M et al (2019) Lateral impacts correlate with falx cerebri displacement and corpus callosum trauma in sports-related concussions. Biomech Model Mechanobiol 18:631-649. https://doi.org/10.1007/ s10237-018-01106-0

Publisher's Note Springer Nature remains neutral with regard to jurisdictional claims in published maps and institutional affiliations. 